\title{
MICROBIAL FUEL CELL A RELIABLE SOURCE FOR RECOVERY OF ELECTRICAL POWER FROM SYNTHETIC WASTEWATER
}

\author{
M. Rahimnejad, \\ G.D. Najafpour ${ }^{2}$, \\ A.A. Ghoreyshi, \\ T. Jafari, \\ F. Haghparast
}

Faculty of Chemical Engineering, Noshirvani University, Babol, Iran

\begin{abstract}
Microbial fuel cells (MFCs) were successfully used as a biological process to remove organic load from synthetic wastewater. Electricity was produced via oxidation of biodegradable organic matter in the presence of active biocatalyst. The system was able to generate clean energy at high efficiency. Wastewater contained organic compound used as substrate in the anaerobic chamber of MFC. The chemical energy generated sufficient electrons which were passed through a resistance to identify current density and liberate electric power as energy source. Acetone as biodegradable substrate with concentration of $3 \mathrm{~g} . \mathrm{l}^{-1}$ was introduced as carbon source in the anode chamber of the MFC. The mixed culture of living microorganisms originated from a biological treatment unit used for anaerobic degradation of organic substrate. The inoculums were supplied by an up flow anaerobic hybrid reactor, a pilot scale bioreactor used for treating pulp and paper wastewater. In this course of treatment, once chemical oxygen demand was removed the current and power was generated while data were recorded via online acquisition system. Also polarization curve was obtained for each set of experiment. In cathode compartment several concentration of ferocynide and potassium permanganate were added to obtain the optimal concentration of oxidizing agents in the cathode chamber. At concentration of 300 $\mu \mathrm{M}$ potassium permanganate, the maximum power and current generated were $22 \mathrm{~mW} . \mathrm{m}^{-}$ ${ }^{2}$ and $70 \mathrm{~mA} \cdot \mathrm{m}^{-2}$, respectively.
\end{abstract}

Keywords: Microbial fuel cell, Bioelectricity, Chemical oxygen demand, Oxidizing agent, Biodegradation of organic waste

\section{INTRODUCTION}

In past two decades, high performance anaerobic processes were found for the treatment of wastewater (Virdis et al., 2008). Energy in the form of methane gas is recovered in the course of anaerobic biodegradation of organic wastes. In contrary low process yield, long duration with low rate of energy production and impurities of methane make the conventional anaerobic process to be less attractive. Recent research interests are seeking for sustainable and clean source of energy with minimal or zero use of carbohydrate (Cha et al., 2010). Microbial fuel cells (MFC) are capable to provide clean source of energy, effective and

\footnotetext{
22Email: najafpour@nit.ac.ir, najafpour8@yahoo.com Tel. / Fax:+98-111-3210975
} 
simultaneous treatment of wastewater (Daniel et al., 2009). The active microorganisms in anaerobic anode chamber of MFCs have capabilities to use inorganic or organic matters present in the wastewater as electron donors through which electricity is generated.

In fact, MFCs are bioreactors that convert chemical energy of organic or inorganic compounds to bioelectrical energy through biocatalytic reactions while microorganisms led to anaerobic conditions (Rezaei et al., 2009). Generally, MFC consists of anode, cathode and cation exchange membrane (Mohan et al., 2008). In development of MFC, various type of materials have been used as electrode, including plain graphite, carbon cloth, graphite foam, graphite granules, and high surface area graphite fiber brush electrodes (He and Angenent, 2006; Fan et al., 2007; Chaudhuri and Lovley, 2003). Cation exchange membranes, anion exchange membranes and ultra filtration membranes are common separators between anode and cathode chambers (Kim et al., 2007; Rozendal et al., 2006). Since cathode has limited oxidation capacity, for high power production in an MFC use of oxidizing agent in cathode is recommended (Yazdi et al., 2008). Various electron accepters, such as ferricyanide and permanganate have been used as catholyte solution in two-chamber MFCs, to enhance the reduction reaction in cathodic compartment (He and Angenent, 2006; Rabaey et al., 2004; You et al., 2006). Oxygen is often used as an electron accepter in cathode compartment because of its high thermodynamic redox potential, good self-sustaining operation, and availability (He and Angenent, 2006).

Wastewater as organic substrate and inexpensive source raw influent is used in MFCs to lead energy production. Most of the energy originated from oxidation of organic load which is converted to electricity while the remaining energy is used for microbial growth (Du et al., 2007; Wang et al., 2008, Aldrovandi, 2009). Currently wastewater MFCs are being considered as a renewable and clean source of energy (Wen et al., 2009).

The purpose of present research was to evaluate the performance of a two chambered MFC with synthetic wastewater as carbon source. The influences of mediator and oxidizing agents on production of bioelectricity in the dual chamber MFC were extensively investigated.

\section{MATERIALS AND METHODS}

Mix strains of microorganisms were obtained from an up-flow hybrid bioreactor operating for the treatment of pulp and paper wastewater. The microorganisms were grown in an anaerobic jar vessel. The medium prepared for seed culture consisted of acetone, yeast extract, $\mathrm{NH}_{4} \mathrm{Cl}, \mathrm{NaH}_{2} \mathrm{PO}_{4}, \mathrm{MgSO}_{4}$ and $\mathrm{MnSo}_{4}:$ 3, 3, 0.2, 0.6, 0.2 and 0.05 g. $1^{-1}$, respectively. The medium was sterilized, autoclaved at $121^{\circ} \mathrm{C}$ and $15 \mathrm{psig}$ for $20 \mathrm{~min}$. The medium $\mathrm{pH}$ was initially adjusted to 6.5 and the inoculums were introduced into the media at ambient temperature. The inoculated cultures were incubated at $30^{\circ} \mathrm{C}$. The bacteria were fully grown for the duration of 24 hours in $100 \mathrm{ml}$ flux without any agitation. Substrate consumption was calculated base on determination of the remaining organic substrate in the culture.

All chemicals and reagents used for the experiments were analytical grades and supplied by Merck (Germany). The pH meter, HANA 211(Romania) model glass-electrode was employed for measuring $\mathrm{pH}$ values of the aqueous phase. The initial $\mathrm{pH}$ of the working solutions was adjusted by addition of diluted $\mathrm{HNO}_{3}$ or $0.1 \mathrm{M} \mathrm{NaOH}$ solutions.

The fabricated cells in the laboratory scale were made of Plexiglas material. The volume of each chamber (anode and cathode chambers) was $650 \mathrm{ml}$ with working volume of $500 \mathrm{ml}$. The sample port was provided for the anode chamber, wire point input and inlet port. The selected electrodes in MFC were Carbon paper in size of . Proton exchange membrane (PEM; NAFION 117, Sigma-Aldrich) was used to separate the two compartments. The ion exchange membrane, Nafion with the area of $9 \mathrm{~cm}^{2}$ separated two chambers. The Nafion as proton exchange membrane was subjected to a course of 
pretreatment to take off any impurities; the film was boiled in $3 \% \mathrm{H}_{2} \mathrm{O}_{2}$ for $1 \mathrm{~h}$, washed with deionized water, $0.5 \mathrm{M} \mathrm{H}_{2} \mathrm{SO}_{4}$, and then washed with deionized water. The anode and cathode compartments were filled by deionized water when the biological fuel cell was not in use to maintain membrane for good conductivity. Neutral red, ferricyanide and permanganate were supplied by Merck (Germany). These chemicals with low concentrations (100 and 200) $\mu \mathrm{mol} . \mathrm{l}^{-1}$ were used as oxidizing agents in cathode chamber. The schematic and photograph diagram and auxiliary equipment of the fabricated MFC cell is shown in Figure 1.

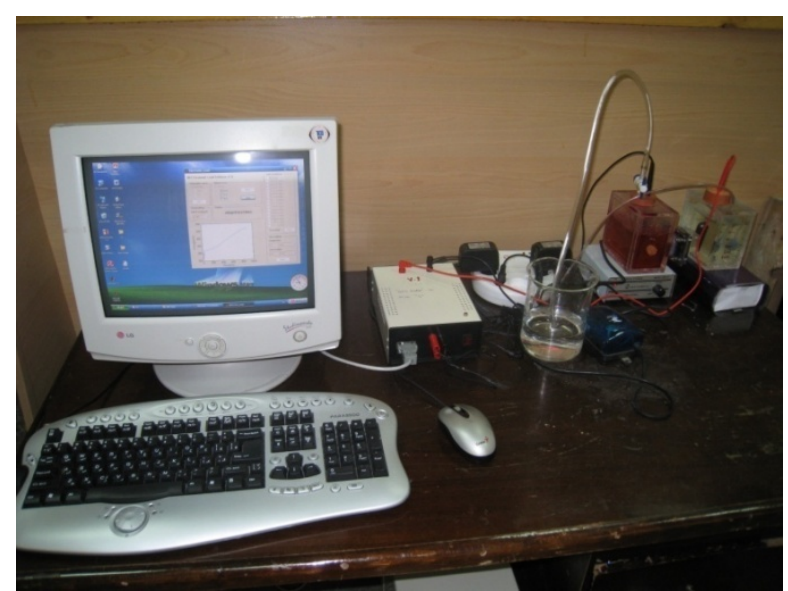

Figure1. Image of the fabricated MFC and online data acquisition system

Cyclic Voltammeter (IVUM soft, Ivium Technology, Netherland) was used to analyze for testing oxidation and reduction of organic matters. The potential range of $-400 \mathrm{mV}$ to 1000 $\mathrm{mV}$ was applied. The working electrode and sense electrode were joined together to measure oxidation and reduction peaks. Carbon paper (NARA, Guro-GU, Seoul, Korea) was used as working electrode and Platinum (Platinum, gauze, 100 mesh, 99.9\% meta basis, Sigma Aldrich) as counter electrode. Also, $\mathrm{Ag} / \mathrm{AgCl}(\mathrm{Ag} / \mathrm{AgCl}$, sat $\mathrm{KCl}$, Sensortechnik Meinsberg, Germany) electrode was utilized as reference electrode. Voltage rate of $50 \mathrm{mV} . \mathrm{S}^{-1}$ was chosen as scan rate in $\mathrm{CV}$ analysis.

\section{RESULTS AND DISCUSSION}

MFCs are an emerging technology that converts the energy retained in organic and inorganic matters directly to useful electrical power. Acetone is one of the organic compounds which are widely produced in chemical industries (Przybylska et al., 2006). Acetone is known as toxic chemical and listed in US-EPA as environmental pollutants (Deng et al., 2004).

A mix strains of microorganisms as inoculums were supplied by an up flow anaerobic hybrid reactor, a pilot scale bioreactor used for treating pulp and paper wastewater. Acetone with concentration of $3 \mathrm{~g} .1^{-1}$ was used as synthetic wastewater in the anode chamber. Production of voltage with respect to time in dual chamber of MFC is shown in Figure 2. At the starting point for the experimental run, the amount produced electricity was very low because of the microorganisms should be adapted with the new environment and utilize acetone for power generation. The logarithmic phase of electricity production started right after 20 hours of incubation time. At 48 hours of operation, the closed circuit potential reached to a maximum and stable value around $198 \mathrm{mV}$. The closed circuit potential was also quite stable for the entire operation, duration of 120 hours. 
Effect of Neutral Red (NR) as electron mediators on power production of MFC at steady state condition was done and the data are illustrated in Figure 2. At 60 and 80 hours of incubation time $100 \mu$ mol.1-1 of NR was added to anode chamber. The obtained data demonstrated that mediators had no significant effect on mixed culture of microorganisms. These microorganisms were able to transfer the generated electrons to anode in absence of mediators. Concentration of wastewater in anode chamber was measured by COD. The COD removal was $69 \%$ at the end of this operation time (Figure 3).

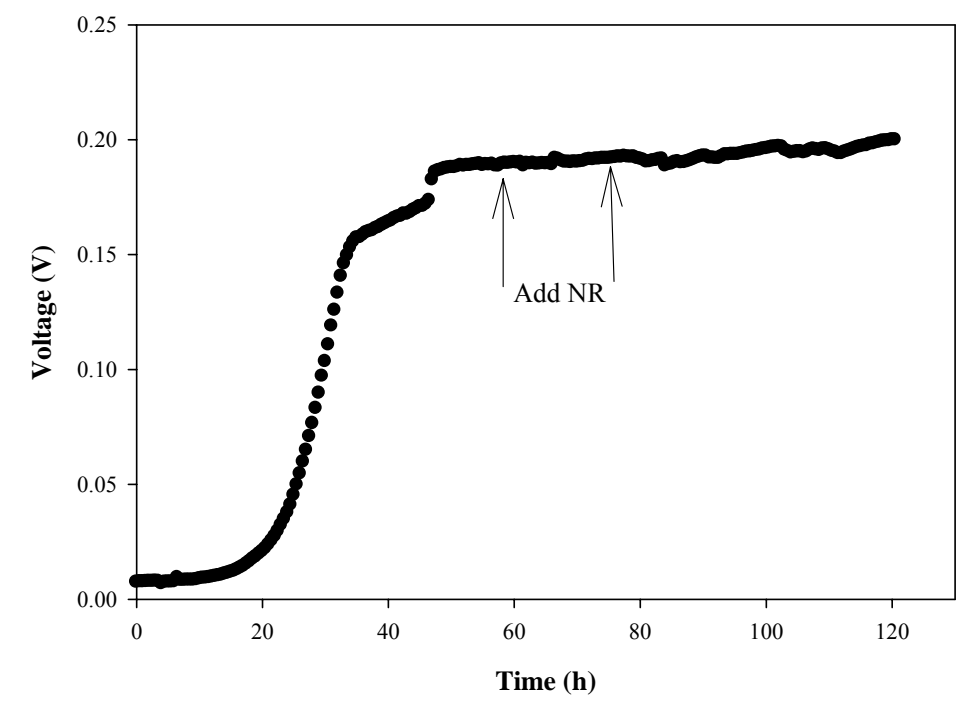

Figure 2: Effect of mediator (NR) on mixed culture in a MFC. Close circuit potential of MFC $\left(\mathrm{R}_{\mathrm{ext}}=1000 \Omega\right)$. Mixed culture originated from wastewater treatment plant.

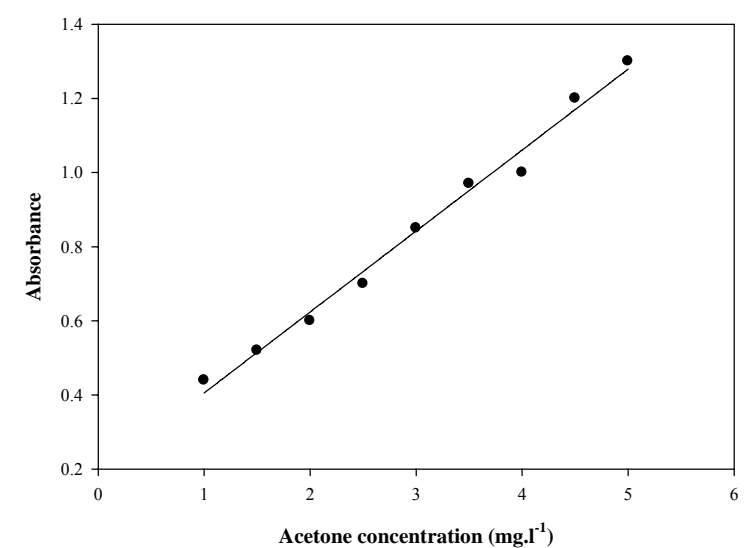

a. Acetone calibration curve

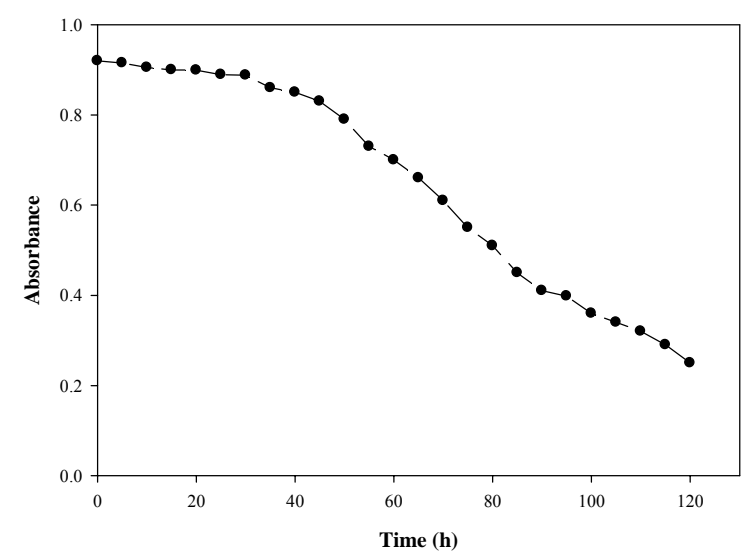

b. Decrease of acetone in MFC

Figure 3: Acetone concentration in the anaerobic anode compartment

The performance of microbial fuel cell was evaluated by polarization curve. Polarization behavior of the fabricated cell was recorded for several external resistances for the determination of maximum power generation. Tablel shows the generated current, power and current in maximum power after 4 days of inoculation. Maximum power and current density without using any oxidizer in the cathode were $2.1 \mathrm{~mW} \cdot \mathrm{m}^{-2}$ and $14 \mathrm{~mA} \cdot \mathrm{m}^{-2}$, respectively. The most common soluble oxidizing agent used for cathodic reaction in MFCs is 
ferricyanide (hexacyanoferrate) (Yazdi et al., 2008). The oxidation reactions may take place in cathode compartment are given as follows:

$$
\begin{aligned}
& {\left[\mathrm{F} e(\mathrm{CN})_{6}\right]^{3-}+e^{-} \rightarrow\left[\mathrm{F}^{\prime} e(\mathrm{CN})_{6}\right]^{4-}} \\
& \mathrm{O}_{2}+\left[\mathrm{F} e(\mathrm{CN})_{6}\right]^{4-}+4 \mathrm{H}^{+} \rightarrow\left[\mathrm{Fe}(\mathrm{CN})_{3}\right]^{3-}+2 \mathrm{H}_{2} \mathrm{O}
\end{aligned}
$$

To enhance electrons transferring to electrode, $50 \mu \mathrm{M}$ ferricyanide was added as an oxidizer to cathode compartment. Potassium ferricyanide acts as a catalyst in order to accelerate the reduction of oxygen in water. Table 1 shows, maximum power increased to $5.3 \mathrm{~mW} . \mathrm{m}^{-2}$, and maximum current density to $21 \mathrm{~mA} \cdot \mathrm{m}^{-2}$. Several concentration $(100,150,200$ and $250 \mu \mathrm{M})$ of ferricyanide were experimented to obtained optimum concentration of ferricyanide. Maximum current and power was obtained at $200 \mu \mathrm{M}$ concentration in cathode chamber.

\begin{tabular}{|c|c|c|c|c|}
\hline $\begin{array}{l}\text { Potassium } \\
\left(\mu \mathrm{mol} .1^{-1}\right)\end{array}$ & ferricyanide & $\begin{array}{r}\mathrm{P}_{\max } \\
\left(\mathrm{mW} \cdot \mathrm{m}^{-2}\right)\end{array}$ & $\begin{array}{l}I \text { in } P_{\max } \\
\left(\mathrm{mA} \cdot \mathrm{m}^{-2}\right)\end{array}$ & $\begin{array}{l}\mathrm{I}_{\max } \\
\left(\mathrm{mA} \cdot \mathrm{m}^{-2}\right)\end{array}$ \\
\hline 0 & 2.1 & 4 & & 14 \\
\hline 50 & 5.3 & 10 & & 21 \\
\hline 100 & 9.2 & 12 & & 38 \\
\hline 150 & 13 & 19 & & 52 \\
\hline 200 & 17 & 28 & & 60 \\
\hline 250 & 17 & 28.4 & & 60.64 \\
\hline
\end{tabular}

Table 1: Effect of ferricyanide concentration at cathode chamber on bioelectricity production

Potassium permanganate has been used as an environmental friendly oxidizing agent in industries. In both acidic and alkaline conditions, permanganate accepts three electrons and thus is reduced to manganese dioxide as illustrated in equations 3 and 4 (You et al., 2006):

$$
\begin{aligned}
& \mathrm{MnO}_{4}^{-}+4 \mathrm{H}^{+}+3 e^{-} \rightarrow \mathrm{MnO}_{2}+2 \mathrm{H}_{2} \mathrm{O} \\
& \mathrm{MnO}_{4}^{-}+2 \mathrm{H}_{2} \mathrm{O}+3 e^{-} \rightarrow \mathrm{MnO}_{2}+4 \mathrm{OH}^{-}
\end{aligned}
$$

Permanganate was used as an oxidizer in the cathode chamber of fabricated MFC. Various concentrations of permanganate (100 to $400 \mu \mathrm{mol} . \mathrm{l}^{-1}$ with an increment of $\left.100 \mu \mathrm{mol} . \mathrm{l}^{-1}\right)$ were experimented and the obtained results as polarization curves are presented in Table 2.

Table 2: Effect of potassium permanganate on power and current production

\begin{tabular}{llll}
\hline $\begin{array}{c}\text { Potassium Permanganate } \\
\left(\mu \mathrm{mol} .1^{-1}\right)\end{array}$ & $\begin{array}{c}\mathrm{P}_{\max } \\
\left(\mathrm{mW} \cdot \mathrm{m}^{-2}\right)\end{array}$ & $\begin{array}{c}\mathrm{I}_{\max } \text { in } \mathrm{P}_{\max } \\
\left(\mathrm{mA} \cdot \mathrm{m}^{-2}\right)\end{array}$ & $\begin{array}{c}\mathrm{I} \\
\left(\mathrm{mA} \cdot \mathrm{m}^{-2}\right)\end{array}$ \\
\hline 0 & 2.1 & 4 & 14 \\
100 & 8.5 & 19 & 34 \\
200 & 14.9 & 31 & 49 \\
300 & 22 & 40 & 72 \\
400 & 22 & 41 & 72.6 \\
\hline
\end{tabular}

Maximum current and power was obtained at permanganate concentration of $300 \mu \mathrm{M}$. The maximum power and current generated were $22 \mathrm{~mW} \cdot \mathrm{m}^{-2}$ and $70 \mathrm{~mA} \cdot \mathrm{m}^{-2}$, respectively. At any concentration greater than the optimum permanganate concentration $(300 \mu \mathrm{M})$ there was no 
significant improvement in current and power generation. The polarization curve for the MFC at the desired concentration of the oxidizer are shown in Figure 4.

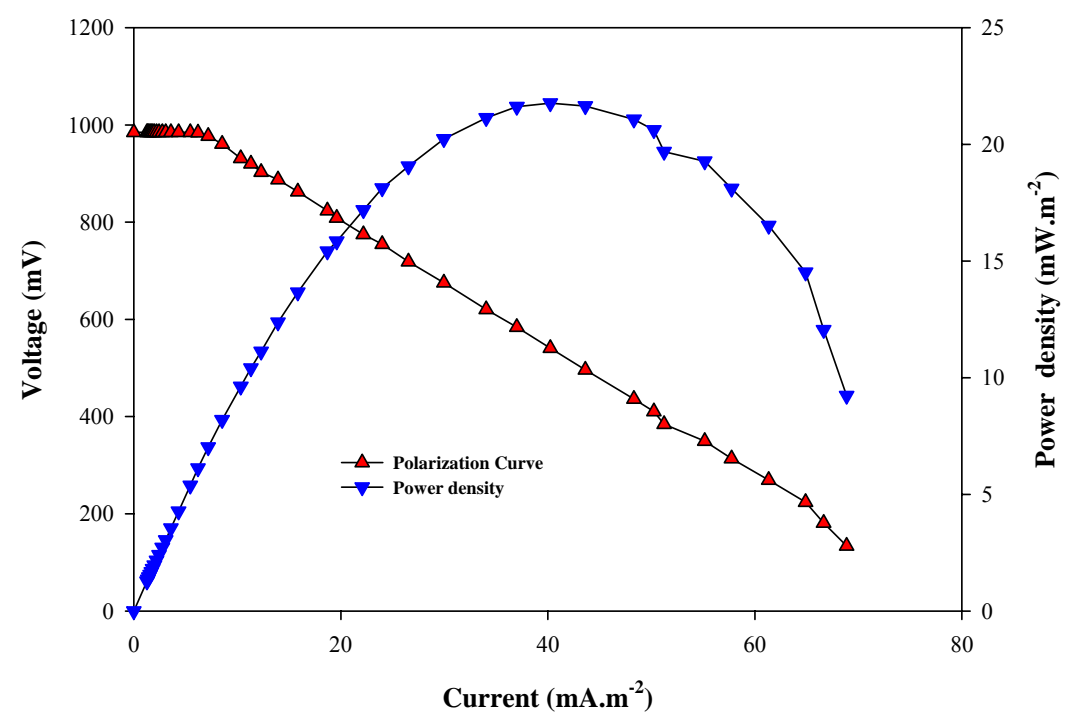

Figure 4: Polarization curve and power density at desired concentration of potassium permanganate

In the next stage, anode electrode with the attached microorganisms was analyzed with $\mathrm{CV}$. The system was analyzed in anaerobic anode chamber. Before formation of any active biofilm on anode surface, no oxidation and reduction potential peak were record in $\mathrm{CV}$ test (Figure $5 \mathrm{a}$ ). Current potential curves by scanning the potential from negative to positive potential after formation of active biofilm are shown in Figure $5 \mathrm{~b}$. Two oxidation and one reduction peak was obtained with $\mathrm{CV}$ test. One peak was obtained in forward scan from -400 to $1000 \mathrm{mV}$ and the other one for oxidation and reduction peak was obtained in reverse scan rate from 1000 to $-400 \mathrm{mV}$. Similar results by alcohol as electron donors in anode chamber was reported (Kim et al., 2007). The first peak was observed in forward scan rate between from -0.087 to $1.6 \mathrm{~V}$.

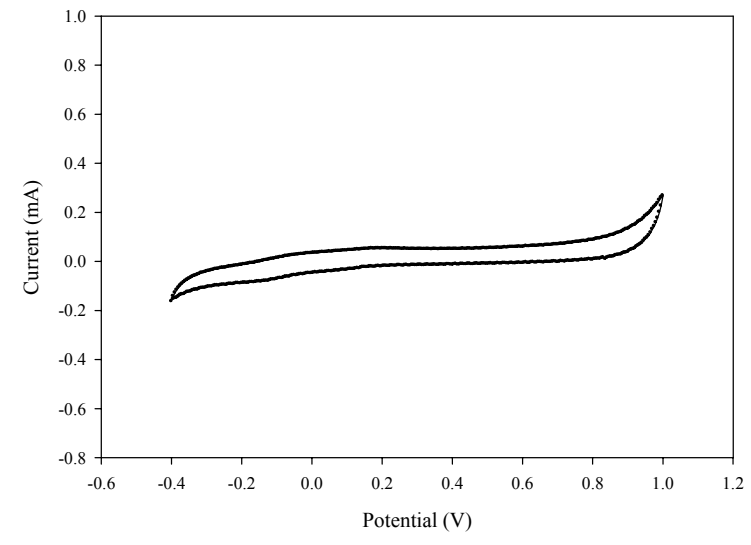

a

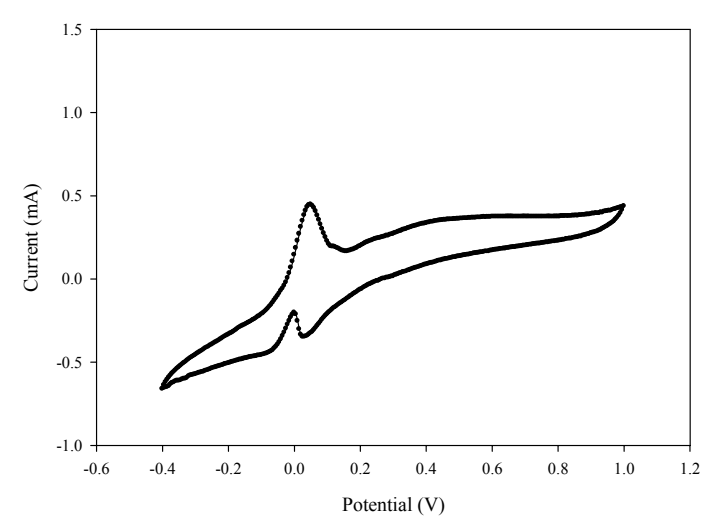

b

Figure 5: Effect of active biofilm on anode surface in CV analysis (a) Absence of biofilm, (b) after formation of biofilm on anode surface 
Before and after the replacement of the growth medium in the anode chamber, CV analysis was evaluated (Figure 6). The obtained results demonstrated that electrochemical activity of attached biocatalyst did not decreased after replacement of medium but also shows the activity increased. This phenomenon demonstrates that the established biofilm on anode enhanced extracellular electron transfer of microorganisms rather than mediators in solution. Otherwise, the electrochemical activity of microorganisms should decreased due to the removal of soluble redox molecules within the anolyte solution.

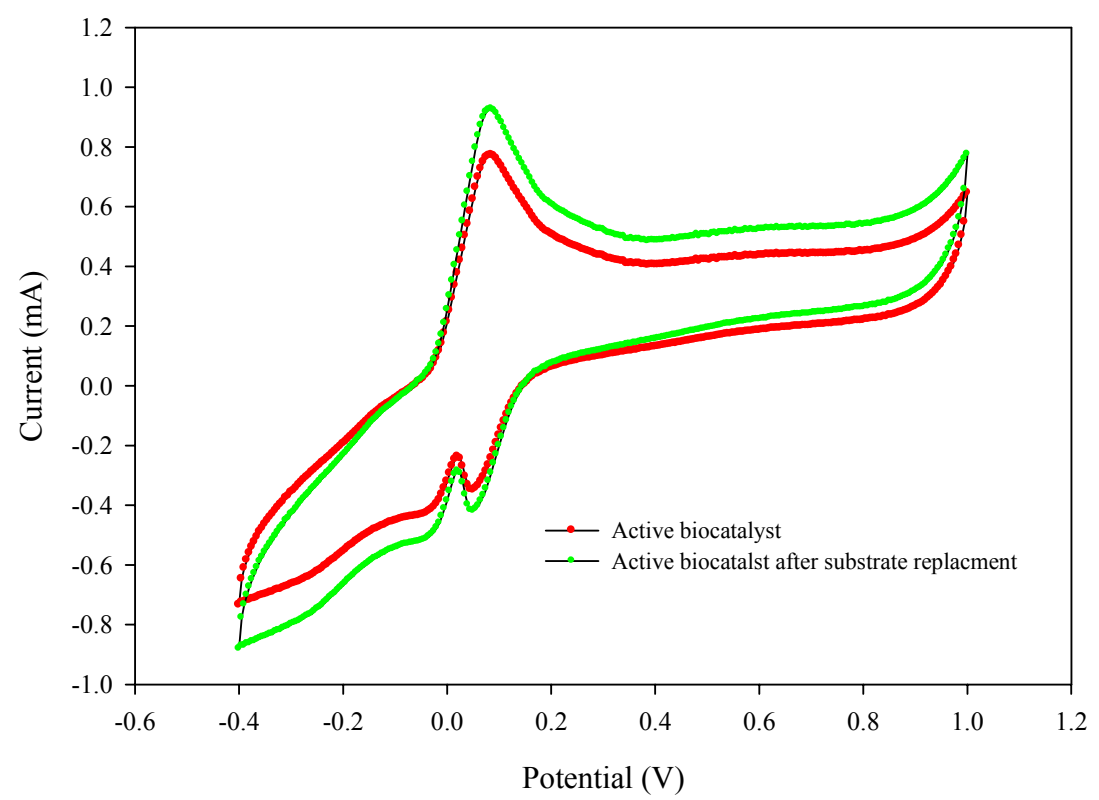

Figure 6: Effect of media on activity of attached microorganisms on anode surface

\section{CONCLUSIONS}

The use of microorganisms as biocatalyst is an interesting issue in MFCs. The MFC is considered as a new source for production of energy in the course of simultaneously wastewater treatment. The present research demonstrates the active biofilm has the ability to generate power from wastewater. Aeration in cathode and use of optimum permanganate concentration may enhance the MFC performances. When the initial permanganate concentration was $300 \mu \mathrm{M}$, maximum current $70 \mathrm{~mA} . \mathrm{m}^{-2}$ was generated. NR as a mediator did not have significant effect on power generation. Attached biofilm of bacteria on anode surface was electrochemically active to transfer electron to anode without any mediators.

\section{ACKNOWLEDGMENTS}

The authors wish to acknowledge Biotechnology Research Center, Noshirvani University of Technology, Babol, Iran for the facilities provided to accomplish this research. 


\section{References}

Aldrovandi A., Marsili E., Stante L., Paganin P., Tabacchioni S. and Giordano A. (2009). Sustainable power production in a membrane-less and mediator-less synthetic wastewater microbial fuel cell. Bioresource Technology, 1:00, 3252-3260

Cha J., Choi S., Yu H., Kim H. and Kim C. (2010). Directly applicable microbial fuel cells in aeration tank for wastewater treatment. Bioelectrochemistry, 78 , 72-79.

Chaudhuri S.K. and Lovley D.R. (2003). Electricity generation by direct oxidation of glucose in mediator less microbial fuel cells. Nature Biotechnology. 21, 1229-1232.

Daniel D.K., Mankidy B., Ambarish K., Manogari R. (2009). Construction and operation of a microbial fuel cell for electricity generation from wastewater. Journal of Hydrogen Energy, $34,7555-7560$.

Deng C., Zhang J., Yu X., Zhang W. and Zhang X. (2004). Determination of acetone in human breath by gas chromatography-mass spectrometry and solid-phase microextraction with on-fiber derivatization. Journal of Chromatography $B, \mathbf{8 1 0}, 269-275$.

Du Z., Li H. and Gu T. (2007). A state of the art review on microbial fuel cells: A promising technology for wastewater treatment and bioenergy. Biotechnology Advances, 25 , 464-482.

Fan Y.Z., Hu H.Q. and Liu H. (2007). Enhanced Coulombic efficiency and power density of air-cathode microbial fuel cells with an improved cell configuration. Power Sources, 171, 383-354.

He Z. and Angenent L.T. (2006). Application of Bacterial Biocathodes in Microbial Fuel Cells. Electroanalysis , 18 , 2009-2015.

Kim J.R., Cheng S., Oh S.E. and Logan B.E. (2007a). Power generation using different cation, anion, and ultrafiltration membranes in microbial fuel cells. Environmental Science and Technology, 41, 1004-1009.

Kim J., Jung S., Regan J. and Logan B. (2007b). Electricity generation and microbial community analysis of alcohol powered microbial fuel cells. Bioresource technology, 98, 2568-2577.

Mohan S.V., Mohanakrishna G., Purushotham B, Saravanan R. and Sarma P.N. (2008) Bioelectricity generation from chemical wastewater treatment in mediatorless (anode) microbial fuel cell (MFC) using selectively enriched hydrogen producing mixed culture under acidophilic microenvironment. Journal of Biochemical Engineering, 39, 121-130.

Pielech-Przybylska K., Ziemin K. and Szopa J.S. (2006) Acetone biodegradation in a trickle-bed biofilter. International Biodeterioration \& Biodegradation, 57, 200-206.

Rabaey K., Boon N. and Siciliano S.D. (2004). Biofuel cells select for microbial consortia that self-mediate electron transfer. Applied and Environmental Microbiology, 70, 53735382.

Rezaei F., Richard T.L. and Logan B.E. (2009). Analysis of chitin particle size on maximum power generation, power longevity,and Coulombic efficiency in solid-substrate microbial fuel cells . Journal of Power Sources, 190, 304-309.

Rozendal R.A., Hamelers H.V.M. and Buisman C.J.N. (2006). Effects of membrane cation transport on $\mathrm{pH}$ and microbial fuel cell performance, Environmental Science and Technology, 47, 5206-5211.

Virdis B., Rabaey K., Yuan Z. and Keller J. (2008). Microbial fuel cells for simultaneous carbon and nitrogen removal. Water Research, 42, 3013-3024 .

Wang X., Feng Y. J. and Lee H. (2008). Electricity production from beer brewery wastewater using single chamber microbial fuel cell. Water Science Technology, 57(7), 1117-1121.

Wen Q., Wu Y., Cao D., Zhao L. and Sun Q. (2009). Electricity generation and modeling of microbial fuel cell from continuous beer brewery wastewater. Bioresource Technology, 100, 4171-4175. 
Yazdi H.R., Carver S.M., Christy A.D. and Tuovinen O.H. (2008). Cathodic limitations in microbial fuel cells: An overview, Power Sources, 180, 683-694.

You S.J., Zhao Q.L. and Zhang J.N.(2006). A microbial fuel cell using permanganate as the cathodic electron acceptor. Power Sources, 162, 1409-1415. 